\title{
Inside information
}

\author{
K. Lewis ${ }^{1}$
}

\section{Key points}

Examines the ways in which primary care dentistry is different from most other parts of health and social care.
Identifies the risks and adverse consequences that can result from some of the widely-held assumptions and misconceptions about primary care dentistry.
Illustrates the need for the 'differentness' of primary care dentistry and its contribution to healthcare to be recognised, understood and valued.

Primary care dentistry is very different from most other parts of healthcare, for a combination of reasons which very few people outside dentistry recognise and understand. This has many undesirable and sometimes serious consequences for dental practitioners. This article argues that unless the views and first-hand experience of dentists is respected and valued, dentists and dentistry will always come off second best when set against the massive scale of medicine, and wider health and social care.

It's a funny old business, primary care dentistry. And here I use the word 'business' advisedly. The fact that dentistry sits within the wider (significantly wider) sphere of healthcare, is very much a double-edged sword because those outside dentistry are plagued with a host of misconceptions about dentistry and about dentists. We rarely have to wait long before reaping the unwelcome consequences of these misunderstandings, urban myths and misconceptions.

One edge of the sword should, in theory, be good news. Dental practice owners have been celebrated as the stars of CQC - with higher levels of compliance than any other group regulated by CQC. Private and NHS hospitals and clinics, medical practices, ambulance services, community-based services, nursing and care homes, hospices and prisons please take note. There are major hot issues and threats - like gross negligence manslaughter and issues connected with $24 / 7$ out of hours etc - which impact medicine much, much more than dentistry. Another is the lowering

${ }^{1}$ Trustee and member of the Transition Board for the College of General Dentistry

Correspondence to: Kevin Lewis

Email: kjlewis_1@hotmail.com

Refereed Paper.

Accepted 7 September 2018

Published online 21 September 2018

DOI: $10.1038 /$ sj.bdj.2018.806 of the court discount rate for personal injury from $+2.5 \%$ to minus $0.75 \% 18$ months ago, which means that the cost of compensating patients who require long-term care as a result of negligent obstetric or other medical care (or other personal injuries) becomes very much greater. This is because instead of an up-front lump sum payment being recognised by allowing it to be discounted - notionally because the recipient has the benefit of being able to invest that money until they need it to fund their care - the reality of the low-risk investment market results in the compensator having to pay an even higher lump sum, rather than a lower one. It may only seem like a swing of $3.25 \%$ but it is applied to amounts of money which are massive in the first place. By way of illustration, NHS Resolution (formerly the NHS Litigation Authority - the agency which handles claims against the NHS) states that the NHS paid out more than $£ 1.63$ billion in damages to claimants in 2017/18, an increase from $£ 1.08$ billion in $2016 / 17 .{ }^{1}$ A third of that increase ( $\$ 404$ million) was directly attributable to the discount rate change, so this is hardly petty cash. The Civil Liabilities Bill has been on its way through parliament either side of the summer recess, and it includes proposals for how the discount rate will be reviewed in the future, by whom and how often.

It is obviously very difficult for NHS Resolution, for the defence organisations
(MDU/MPS/MDDUS) and for any other insurer/indemnifier who has significant exposure to medical members/policyholders in terms of both their ability to carry adequate reserves for these huge medical claims, whether they already know about them or are as yet oblivious to their potential existence, and also when trying to set subscriptions/premiums for the future. Most of these organisations indemnify/insure dentists as well as medics so while they may not be dental cases, they could have repercussions for dental indemnity costs in the future.

Other contrasts with our medical colleagues may be less dramatic in scale but are also striking. Most patient contacts in dentistry are with healthy, ambulant patients who have no presenting symptoms, and they take place in privately owned primary care settings rather than in publicly owned hospitals and clinics. Elective treatment is more a feature of dentistry, and there is a lot more private dentistry than private medicine. In dentistry, the line between NHS and private treatment is at best indistinct and blurred, and treatment of both kinds is often mixed, even for the same patient at the same visit on the same day. Crucially, dentistry has a more obvious commercial dimension, not least because money changes hands much more often in primary care dentistry than in any area of medicine. This makes a huge difference, as I will seek to explain. 


\section{Sins of assumption}

The NHS is overwhelmingly preoccupied with medicine and many other areas of healthcare and several healthcare professions exist primarily to support that - the ambulance services, the nursing and midwifery professions, physiotherapists, etc. Latterly there has been a recognition that social care is also inextricably linked to healthcare, and the resulting union creates a behemoth which demands and consumes resources (financial and human) on a staggering scale. Almost all of this is - unlike dentistry - free at the point of delivery, which removes a major driver for complaints and (sometimes) litigation that remains an ever-present risk in dentistry. It is a recognised fact that UK medics have fewer complaints and fewer negligence claims per head than UK dentists. Instead of concluding from this that there is a problem with UK dentists - as the GDC did in $2014^{2}$ - one could instead make the effort to understand the differentiating factors which contribute to and help to explain this situation. Then - and only then - you can address the right issues in the right way. Another obvious and increasingly relevant example is the penetration and influence, and the professional and regulatory interface with the corporates. Taking four examples, this is very different for the medics, for pharmacists, for opticians and for dentists. One size certainly doesn't fit all and because the devil is in the differences, you need to really understand them rather than simply assuming that you do.

The stage for most surgeons is a hospital operating theatre. General dental practitioners are more like 'procedural' GPs in that they spend their time carrying out clinical/ surgical procedures in an outpatient/'high street' setting. In doing this they must provide their own premises, equipment, instruments, materials, staff, insurance/indemnity etc, without any government subsidy. The numbers of procedures they carry out, and the number of patients they treat, make most hospital units look like part-time training establishments. Dental practice owners must make this work financially just like any other business where income needs to exceed expenditure, but in NHS dentistry you have no control over what you charge or what you get paid, even though the NHS seeks to exert absolute control over what you do, how and when. As business environments go, it is a pretty bizarre situation.

For all the right reasons, and a few of the more questionable ones, there has been a huge emphasis upon patient safety, treatment standards and the quality of care. The expected standard is the same whether or not you are being paid at all, whether you are being paid enough to cover the true cost of achieving and maintaining that standard, whether you are working privately or on the NHS. The expected standard is the same irrespective of where you are located and what your operating costs are, and even if you are simply trying to survive and care for your patients in the carnage that is UDA-land - a source of malevolent devastation inflicted from outside and over which you have no control.

All of this results in some truly extraordinary situations which only non-dentists and lay people fail to understand. But not all dentists get it either. There are some who don't work in the NHS, who provide expert evidence in claims litigation or a GDC investigation insisting that anything less than a roll of wallpaper's worth of clinical records (or its electronic equivalent) is insufficient. There are people who have never owned or operated a dental practice but are full of bright ideas about how they should be run and why practices should continue to accept patients in the certain expectation that they will be working pro-bono and making a financial loss. Their choice, not infrequently, being between losing money through a clawback, or losing money because their income will be outstripped by their costs. Nobody outside dentistry would believe that, let alone understand it.

\section{Dishonesty}

A lot of what the GDC has a habit of construing as being suggestive of 'dishonesty' is not remotely dishonest in either its intent or the action (or inaction) itself. It might seem so to a lay caseworker whose preconceptions or training lean them in that direction, but it is wrong that dentists should be the ones who end up suffering the consequences of that. It is a hurtful and serious allegation. If in due course the threatened reforms of UK healthcare regulation do end up lumping dental registrants in with large battalions of people who in practical terms have very little in common with us, it will be largely to our detriment because we will be judged by the norms of the battalion, even though they might inhabit a different world. But then again I am not aware of any other healthcare regulator that goes this far out of its way to find evidence of 'dishonesty' nor to impute dishonesty into honest and/or innocent actions.

The 'differentness' of dentistry is a source of great irritation to some, who often appear to find us a time-consuming irritation and distraction. They really should learn to get over it and accept the many attributes that we bring to the healthcare party - and also the fact that dental practices have already spent many years operating successfully in the real world that most of medicine and healthcare resists and is so terrified of. Yet for some reason that I find mystifying, there seems to be precious little appetite outside dentistry to learn about that 'differentness' and its practical implications and how the rest of healthcare can learn from our experiences. And that becomes a problem in itself.

The phrase 'It takes one to know one' is generally used in a pejorative sense, but I would use it here in a more benevolent way because it captures the essence of what I am trying to say. Dentists will generally get more empathy and a more sympathetic ear from other dentists, coupled with an enhanced level of shared understanding and a greater willingness to listen and engage with the issues. We deserve better than to be a continual afterthought - although even that is preferable to not being thought of very much at all.

1. NHS Litigation Authority. Annual report and accounts 2017/18. Available from https://resolution.nhs.uk/ wp-content/uploads/2018/07/NHS-Resolution-Annual-Report-2017-2018_digital.pdf (accessed September 2018)

2. William Moyes; Chair, General Dental Council. Pendlebury Lecture to Faculty of General Dental Practitioners (UK), June 2014 